\title{
CORRIGENDUM
}

\section{PREDATION ON PROKARYOTES IN THE WATER COLUMN AND ITS ECOLOGICAL IMPLICATIONS}

\section{Jakob Pernthaler}

Nature Reviews Microbiology 3, 537-546 (2005), doi:10.1038/nrmicro1180

In the above article, the following passage of text on page 542 might have been misleading: 'Some bacteria can even poison their predators in a concerted manner: Chromobacterium violaceum specifically induced the eukaryotic APOPTOTIC RESPONSE after being ingested by a flagellate ${ }^{105}$. The constitutive production of the toxic agent, violacein, was only observed in strains that were capable of quorum sensing.' It should have read: 'Some bacteria can even poison their predators in a concerted manner: Chromobacterium violaceum caused rapid cell death after being ingested by a flagellate ${ }^{105}$. The toxic agent violacein is known to induce the APOPTOTIC RESPONSE in eukaryotic cells ${ }^{105 a}$. Its constitutive production was only observed in strains that were capable of quorum sensing.'

The author apologizes to readers for any confusion caused.

105a. Melo, P. S., Justo, G. Z., de Azevedo, M. B., Duran, N. \& Haun, M. Violacein and its $\beta$-cyclodextrin complexes induce apoptosis and differentiation in HL60 cells. Toxicology 186, 217-225 (2003).

\section{ERRATUM}

Also in this article, a global formatting problem unfortunately resulted in all units in $\mu \mathrm{m}$ being mistakenly changed to $\mathrm{mm}$. We wish to apologize to the author, and to readers, for any confusion caused. 